\title{
A Novel Inner Ear Monitoring System for Evaluating Ototoxicity of Gentamicin Eardrops in Guinea Pigs
}

Ting-Hua Yang, MD; Shing-Hwa Liu, PhD; Yi-Ho Young, MD

Objective/Hypothesis: Although most studies have identified damage in the cochlea and semicircular canals as the primary sites of aminoglycoside toxicity, little attention has been devoted to the toxic effects on the otolithic organs. This study aimed to assess the toxic effect of gentamicin eardrops on the inner ear end organs via a novel inner ear monitoring system combined with morphological examination.

Study Design: Prospective study.

Methods: Guinea pigs were treated with 50 $\mu \mathrm{L}$ saline $(\mathrm{n}=10)$ and $50 \mu \mathrm{L}$ gentamicin $(40 \mathrm{mg} /$ $\mathrm{mL} ; \mathrm{n}=10$ ) on the right and left round window membranes, respectively. An inner ear monitoring system, including auditory brainstem response $(\mathrm{ABR})$, caloric, ocular vestibular-evoked myogenic potential (oVEMP), and cervical VEMP (cVEMP) tests, was used to assess ototoxicity in guinea pigs at 2 weeks after treatment. The animals were then sacrificed for morphological study via confocal microscopy.

Results: Normal results in ABR, caloric, cVEMP, and oVEMP tests were shown in all saline-treated ears, whereas elevated ABR threshold and absent responses in caloric, oVEMP, and cVEMP tests were noted in all gentamicin-treated ears. The cochlear and vestibular explants harvested from the gentamicin-treated ears revealed substantial loss of hair cells.

Conclusions: The inner ear monitoring system, including $\mathrm{ABR}$, caloric, oVEMP, and cVEMP tests, might help to evaluate toxicity information of the topical eardrops or agents on the inner ear end organs,

From the Institute of Toxicology, College of Medicine (T.-H.Y., S.-H.L.); and the Department of Otolaryngology (T.-H.Y., Y.-H.Y.), National Taiwan University, Taipei, Taiwan. 2,2010

Editor's Note: This Manuscript was accepted for publication March

This work was supported by the National Science Council (grant no. NSC 97-2314-B002-094-MY3) and National Taiwan University Hospital (no. NTUH97-M-1009), Taipei, Taiwan. The authors have no other funding, financial relationships, or conflicts of interest to disclose.

Send correspondence to Yi-Ho Young, MD, Department of Otolaryngology, National Taiwan University Hospital, 1, Chang-Te St., Taipei, Taiwan. E-mail: youngyh@ntu.edu.tw

DOI: $10.1002 /$ lary.20923 including cochlea, semicircular canals, utricle, and saccule.

Key Words: Eardrops, gentamicin, ototoxicity, cervical vestibular-evoked myogenic potential, ocular vestibular-evoked myogenic potential.

Level of Evidence: $2 c$.

Laryngoscope, 120:1220-1226, 2010

\section{INTRODUCTION}

It is well known that aminoglycoside eardrops can combat the gram-negative bacterial infection of the ear, but its toxicity is also noted with different susceptibilities in cochlear and vestibular sensory cells. ${ }^{1}$ Among the members of the aminoglycoside family, gentamicin can selectively destroy human vestibular hair cells and severely impair vestibular function. ${ }^{2}$ Thus, intratympanic gentamicin administration has become the preferred treatment for intractable vertigo in cases of Meniere's disease. ${ }^{3}$ Although most studies have identified damage in the cochlea and semicircular canals as the primary sites of aminoglycoside toxicity, ${ }^{4,5}$ little attention has been devoted to the effect on the otolithic organs. ${ }^{6}$

Recently, it has been established that all the inner ear end organs can be assessed in humans via a sensitive monitoring system that comprises auditory brainstem response (ABR) for cochlear function, caloric test for the function of semicircular canals, ocular vestibular-evoked myogenic potential (oVEMP) and cervical vestibularevoked myogenic potential (cVEMP) tests for assessing the function of utricle and saccule, respectively. ${ }^{7}$ In experimental animals, we have reported that absent cVEMPs in gentamicin-treated guinea pigs is likely due to saccular toxicity, ${ }^{8}$ and histological analyses demonstrated that morphological changes occur mostly in type I hair cells of the saccular macula. ${ }^{9}$ However, morphological and functional evaluation of the utricle after gentamicin treatment remains less investigated, leaving the study of ototoxicity incomplete. Therefore, this study aimed to assess the toxic effect of gentamicin eardrops on the inner ear end organs via a novel inner ear monitoring system combined with morphological examination. 


\section{MATERIALS AND METHODS}

Application of Eardrops

Randomly bred Hartley guinea pigs $(\mathrm{n}=10)$ weighing 200 to $220 \mathrm{~g}$ were used. Under general anesthesia with intraperitoneal pentobarbital sodium ( $35 \mathrm{mg} / \mathrm{kg}$ ), both tympanic bullae were opened to expose the round window membranes under an operating microscope. A solution of $50 \mu \mathrm{L}$ saline and gentamicin $(40$ $\mathrm{mg} / \mathrm{mL}$ ) was dropped on the right and left round window membranes, respectively. The rationale for the dosage selection was based on the use of 0.3 to $0.6 \mathrm{~mL}$ gentamicin for humans, ${ }^{3}$ with one tenth of this dose being administered to the guinea pigs. ${ }^{8}$ Then, incision wounds were sutured and the animals were kept in the recumbent position with the left ear pointed upward to ensure contact of gentamicin with the round window membrane until the animals awoke, approximately 6 hours after treatment. Animals were housed at $23 \pm 2{ }^{\circ} \mathrm{C}$ and $55 \% \pm 5 \%$ humidity and fed a solid diet and tap water ad libitum. At 2 weeks after treatment, each animal underwent caloric, oVEMP, and cVEMP tests without anesthesia, followed by an ABR test under general anesthesia, and was then sacrificed for morphological study.

This study was approved by the institutional review board and was conducted in accordance with the guideline for the care and use of laboratory animals by the Animal Research Committee in National Taiwan University, College of Medicine.

\section{Caloric Test}

The guinea pig was restrained by a special clamp, with its head fixed and four legs left free. A pair of clip electrodes was attached to the bilateral canthi, and a reference electrode was attached to the vertex at the midline. Ice water $\left(0^{\circ} \mathrm{C}, 5 \mathrm{~mL}\right)$ was used to irrigate the ear canal for 5 seconds with the animal in a prone position. Recordings were made with a two-channel electronystagmographic recorder (NY-13 Rion Co., Tokyo, Japan). Both the caloric nystagmus and its slow phase velocity were recorded. Once the response was absent, the animal was resubjected to the caloric test again after an intermission of 5 minutes. ${ }^{10}$

\section{oVEMP Test}

The guinea pig was fixed with its head in a prone position. Five subdermal needle electrodes $(13.0 \times 0.4 \mathrm{~mm}$; ES43-838; Technomed Europe, Maastricht, The Netherlands) were employed. Two active electrodes were inserted vertically on the skin $5 \mathrm{~mm}$ below the inferior orbital rim to be adjacent to the inferior extraocular muscles without force bilaterally. Another two reference electrodes were inserted approximately $15 \mathrm{~mm}$ below the respective active ones. The ground electrode was placed on the parietal area at the midline. Single square wave stimuli of $0.6 \mathrm{~ms}$ in duration were transmitted from a hand-held vibrator (V201 shaker; Ling Dynamic Systems, Royston, England) with $1.81 \mathrm{~kg}$ in weight, 9.6 $\mathrm{cm}$ in height, and $7.8 \mathrm{~cm}$ in diameter for head vibration, which was driven by a custom amplifier. Drive voltage was adjusted and fixed to produce a peak force level of $139 \mathrm{~dB}(1 \mu \mathrm{N})$ from the vibrator, as measured by an artificial mastoid (model 4930; Bruel and Kjaer P/L, Naerum, Denmark). The operator held the vibrator by hand and supported most of its weight such that the pole tip delivered a repeatable tap on the midline frontal bone of a guinea pig. During recording (Smart EP 3.90; Intelligent Hearing Systems, Miami, FL), electromyographic (EMG) signals were amplified and bandpass filtered to 1 to $1,000 \mathrm{~Hz}$. Stimulation rate was $5 \mathrm{~Hz}$, analysis time for each response was $24 \mathrm{~ms}$, and 30 responses were averaged for each run.

The initial negative-positive biphasic waveform comprised peaks $\mathrm{nI}$ and $\mathrm{pI}$. Consecutive runs were performed to confirm

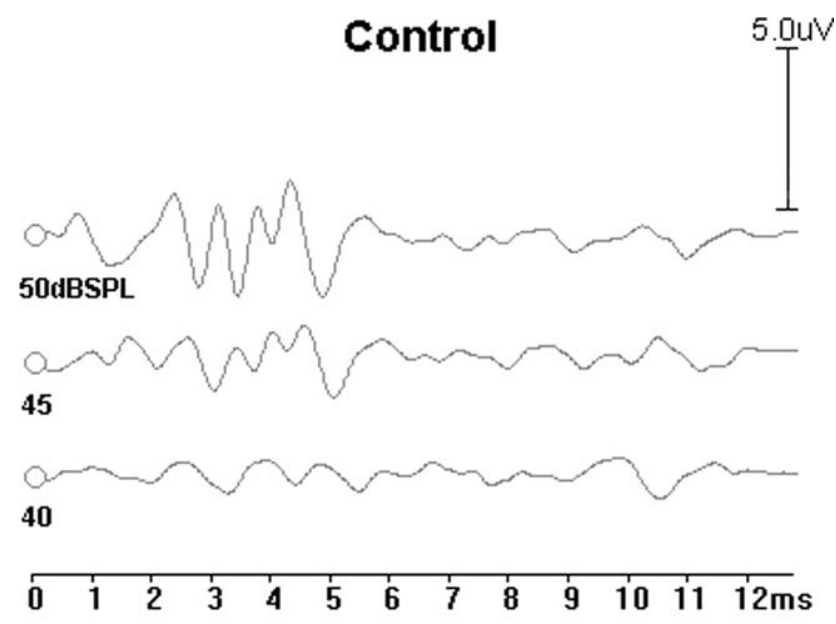

Gentamicin


\begin{tabular}{lllllllllllll}
\hline 0 & 1 & 2 & 3 & 4 & 5 & 6 & 7 & 8 & 9 & 10 & 11 & $12 \mathrm{~ms}$
\end{tabular}

Fig. 1. Auditory brainstem responses (ABR) in a guinea pig at 2 weeks after intratympanic administration of saline (control) and gentamicin $(40 \mathrm{mg} / \mathrm{mL})$ in each ear. The saline-treated ear reveals an $\mathrm{ABR}$ threshold of $45 \mathrm{~dB}$ SPL, whereas the gentamicin-treated ear shows an ABR threshold of $65 \mathrm{~dB}$ SPL.

the reproducibility of peaks $\mathrm{nI}$ and $\mathrm{pI}$, which were interpreted by two independent observers, and oVEMPs were deemed to be present. Conversely, oVEMPs were deemed to be absent when the biphasic waveform was not reproducible.

\section{cVEMP Test}

A pair of needle electrodes were placed on both neck extensors at the level of third cervical vertebral bone while a reference electrode was placed on the occipital area at the midline, and EMG activity was recorded. During the recording, the animal was fixed with its head elevated and neck extended in a prone position throughout the entire test. EMG signals were amplified and bandpass filtered between 30 and $3000 \mathrm{~Hz}$. Click stimuli $(0.1 \mathrm{~ms})$ were generated by an earphone connected via a short tube inserted into the ear canal. Each animal was evoked by monaural acoustic stimulation with unilateral recording. The stimulation rate was $5 \mathrm{~Hz}$ and the analysis time for each response was $24 \mathrm{~ms} ; 200$ responses were averaged for each run.

Each animal underwent a serial cVEMP testing with the stimulus intensity of $120 \mathrm{~dB}$ sound pressure level (SPL). The positive/negative polarities of biphasic waveforms were termed waves I and II based on their latencies of approximately $6 \mathrm{~ms}$ and $9 \mathrm{~ms}$, respectively. Subsequently, the latencies of positive peak I, negative peak II, and peak-to-peak I-II amplitude were measured. ${ }^{11}$ 
TABLE I.

Results Via Inner Ear Monitoring System of Guinea Pigs at Two Weeks After Gentamicin Treatment.

\begin{tabular}{lcc}
\hline & $\begin{array}{c}\text { Saline-Treated } \\
\text { Ear* }^{*}\end{array}$ & $\begin{array}{c}\text { Gentamicin-Treated } \\
\text { Ear* }^{*}\end{array}$ \\
\hline No. ears & 10 & 10 \\
ABR threshold (dB SPL) & $46 \pm 4$ & $64 \pm 6$ \\
Caloric & $55 \pm 25$ & 0 \\
$\quad$ Duration (sec) & $5.0 \pm 1.6$ & 0 \\
SPV ( $/ \mathrm{sec})$ & & \\
oVEMP & $3.21 \pm 0.39$ & 0 \\
nl latency (ms) & $4.80 \pm 0.29$ & 0 \\
pl latency (ms) & $67.3 \pm 47.8$ & 0 \\
nl-pl amplitude $(\mu \mathrm{V})$ & & \\
cVEMP & $6.41 \pm 0.78$ & 0 \\
Positive I latency (ms) & $7.42 \pm 0.52$ & 0 \\
Negative II latency (ms) & $5.75 \pm 1.95$ & 0 \\
I-II amplitude $(\mu \mathrm{V})$ &
\end{tabular}

Data are expressed as mean \pm standard deviation.

${ }^{\star} P<.01$, Mann-Whitney $U$ test.

$\mathrm{ABR}=$ auditory brainstem response. SPV = slow phase velocity.

\section{$A B R$}

Under intraperitoneal anesthesia with pentobarbital sodium $(35 \mathrm{mg} / \mathrm{kg})$, a pair of needle electrodes were placed onto the vertex and the ipsilateral retroauricular region, and a ground electrode was placed on the neck. Click stimuli $(0.1 \mathrm{~ms})$ were delivered through a plastic tube inserted into the ear canal (Smart EP 3.90; Intelligent Hearing Systems). The repetition rate was $20 \mathrm{~Hz}$, and 400 sweeps were averaged. The stimulus intensity was from $100 \mathrm{~dB}$ SPL initially, followed by a 5 - $\mathrm{dB}$ step decrement until the absence of the waveforms, and the threshold of ABR was thus determined. ${ }^{8}$

\section{Morphological Study}

Having finished the audiovestibular function testing, guinea pigs were sacrificed after deep anesthesia with pentobarbital $(50 \mathrm{mg} / \mathrm{kg})$ intraperitoneally. The cochlear and vestibular explants were first fixated with $4 \%$ paraformaldehyde and $1 \%$ glutaraldehyde in phosphate buffered saline (PBS) for 20 minutes at $20^{\circ} \mathrm{C}$, and then permeabilized with $5 \%$ Triton X-100 in PBS with $10 \%$ fetal bovine serum for 30 minutes. Explants were stained with a conjugated rhodamine-phalloidin probe (1:100, Texas Red X-phalloidin; Molecular Probes, Eugene, OR) in PBS for 1 hour. Phalloidin specifically binds to F-actin, which is abundant in the stereocilia and cuticular plate of the hair cells. When the fluorescent dye rhodamine conjugates with phalloidin, it emits red fluorescence and labels F-actin. The tissues were then washed three times with PBS and mounted on glass slides with Fluoromount (Molecular Probes). Finally, the slides were examined via confocal microscopy (Zeiss LSM 510 Meta; Carl Zeiss AG, Oberkochen, Germany). The excitation
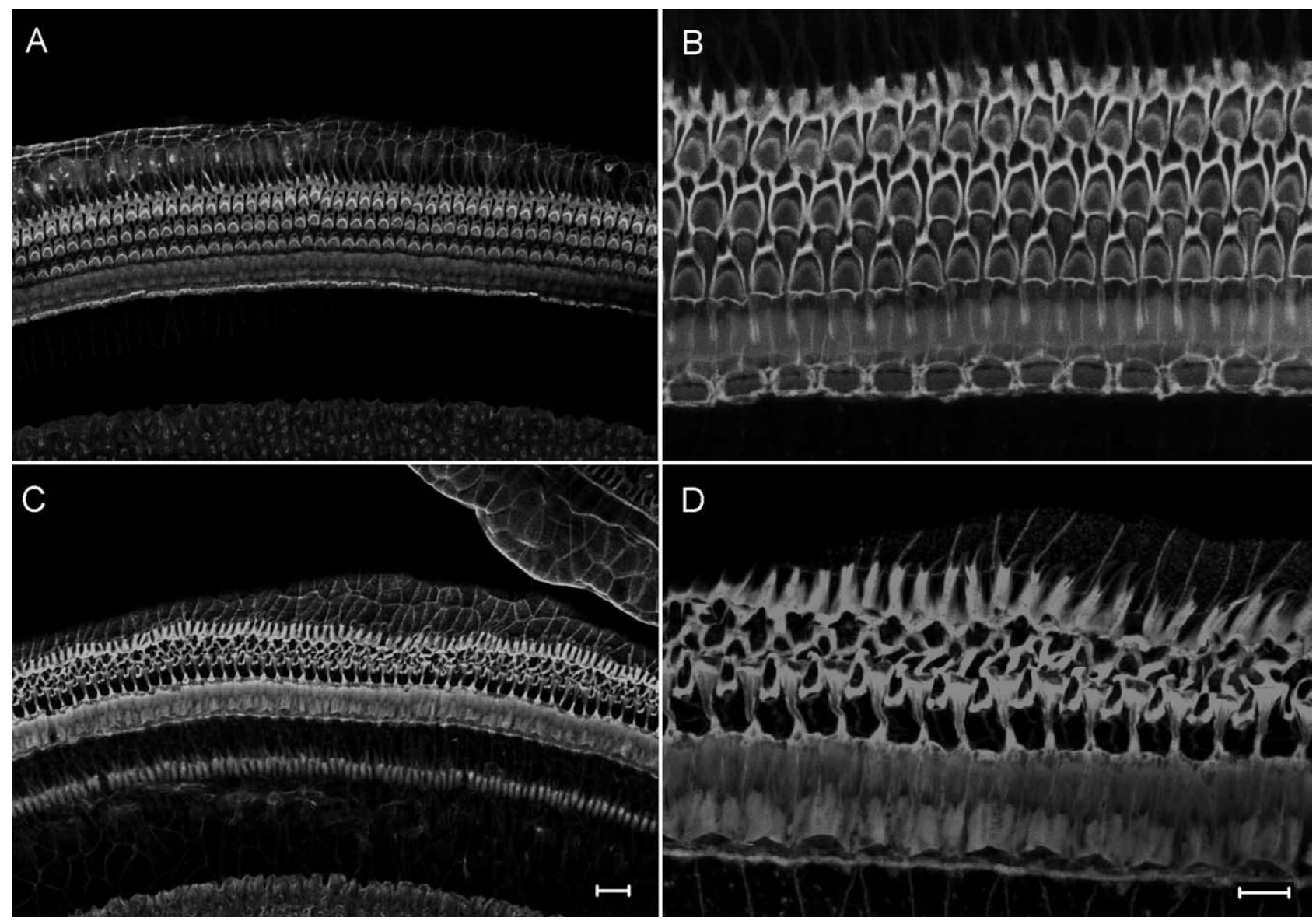

Fig. 2. Cochlear explants taken from guinea pigs 2 weeks after treatment with saline $(A, B)$ and gentamicin (C, D). (A, B) No observable morphological changes are noted. (C, D) Loss of hair cells are shown. Hair cells are labeled with rhodamine-phalloidin. Bar $=20 \mu \mathrm{m}$ (A, C) or $10 \mu \mathrm{m}$ (B, D). 
wavelength was $561 \mathrm{~nm}$, and the emission wavelength was long-pass filtered over $575 \mathrm{~nm}$.

\section{Statistical Methods}

The mean ABR threshold, the characteristic parameters (latency and amplitude) of the cVEMP and oVEMP, as well as the duration and slow phase velocity of the caloric nystagmus were compared between the saline- and gentamicin-treated ears by Mann-Whitney $U$ test. A significant difference indicates $P<.05$.

\section{RESULTS}

\section{Cochlear Part}

The ABR waveforms were elicited at all saline- and gentamicin-treated ears, with the mean ABR thresholds of $46 \pm 4$ and $64 \pm 6 \mathrm{~dB}$ SPL, respectively (Fig. 1). The gentamicin-treated ears exhibited a significantly elevated $\mathrm{ABR}$ threshold when compared with the salinetreated ears $(P<.01$, Mann-Whitney $U$ test) (Table I). Morphologically, the cochlear explants harvested from guinea pigs demonstrated substantial loss of hair cells in gentamicin-treated ears, whereas normal morphology was noted in saline-treated ears (Fig. 2)

\section{Vestibular Part}

All saline-treated ears revealed normal caloric responses (Fig. 3), with the duration and slow phase velocity of the caloric nystagmus of $55 \pm 25 \mathrm{sec}$ and

\section{Control}

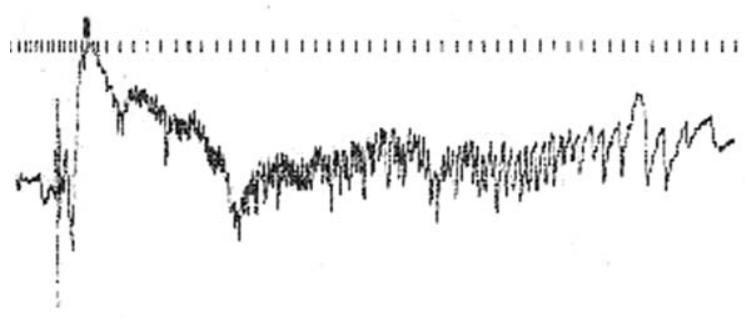

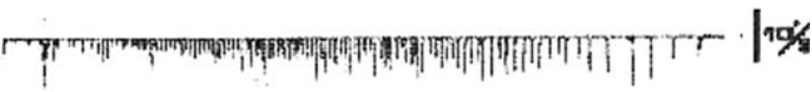

\section{Gentamicin}

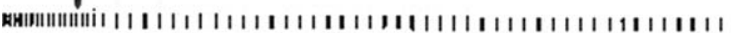

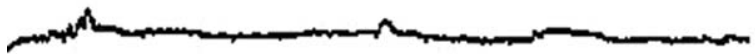

Fig. 3. Caloric tests in a guinea pig. The control (top) ear reveals normal caloric responses, but gentamicin-treated (bottom) ear shows absent response. Upper trace, time base; middle trace, eye movement; lower trace, slow phase velocity; mark above upper trace, end of irrigation.
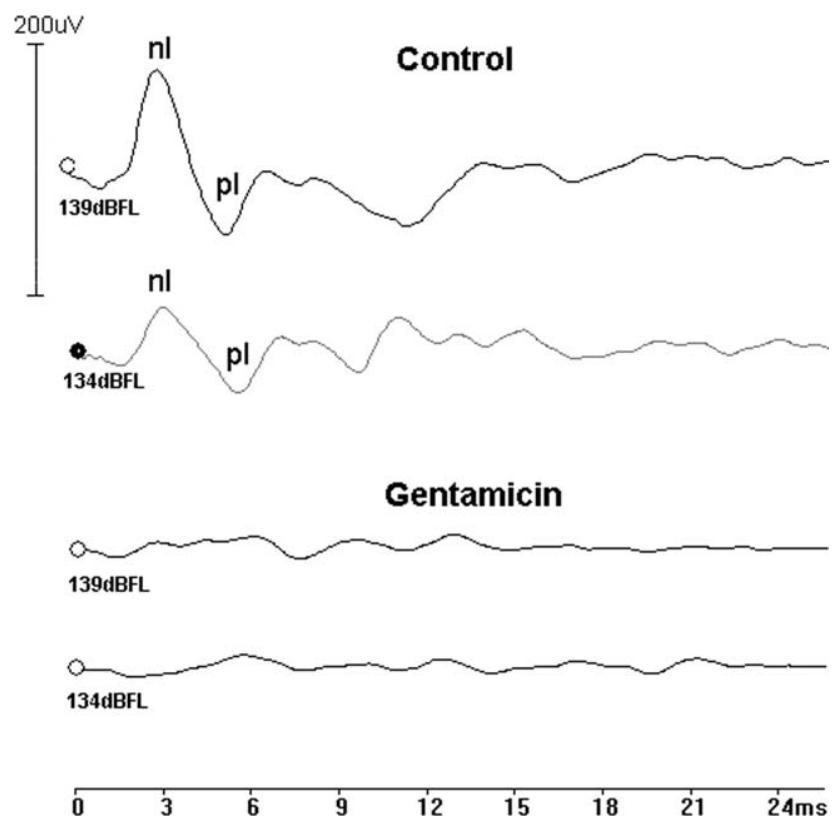

Fig. 4. Ocular vestibular-evoked myogenic potential tests in a guinea pig. The saline-treated ear reveals normal biphasic nl-pl responses, but the gentamicin-treated ear shows absent response.

$5.0 \pm 1.6 \%$ sec, respectively (Table I). Conversely, none of the gentamicin-treated ears showed caloric response (Fig. 3).

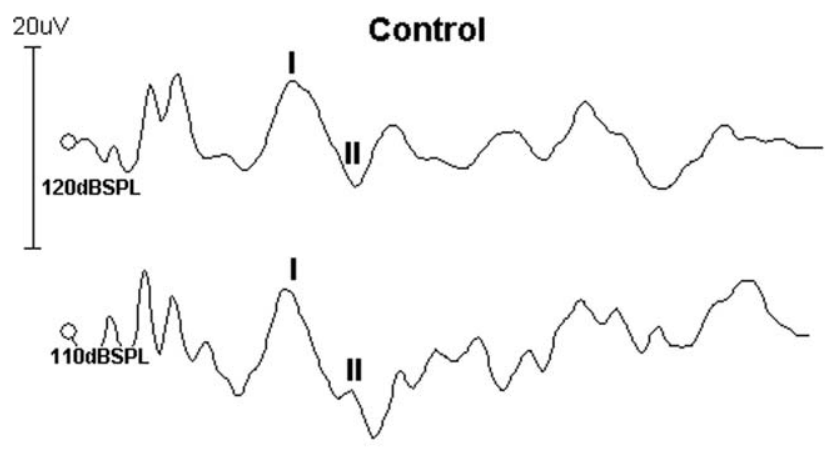

\section{Gentamicin}

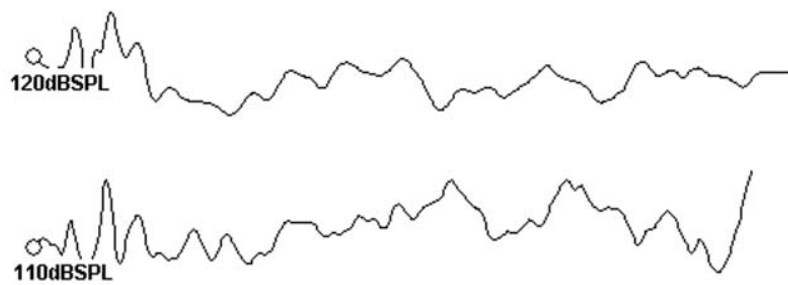

\begin{tabular}{lllllllll}
\hline 0 & 3 & 6 & 9 & 12 & 15 & 18 & 21 & $24 \mathrm{~ms}$
\end{tabular}

Fig. 5. Cervical vestibular-evoked myogenic potential tests in a guinea pig. The saline-treated ear reveals normal biphasic I-II responses, but the gentamicin-treated ear shows absent response. 

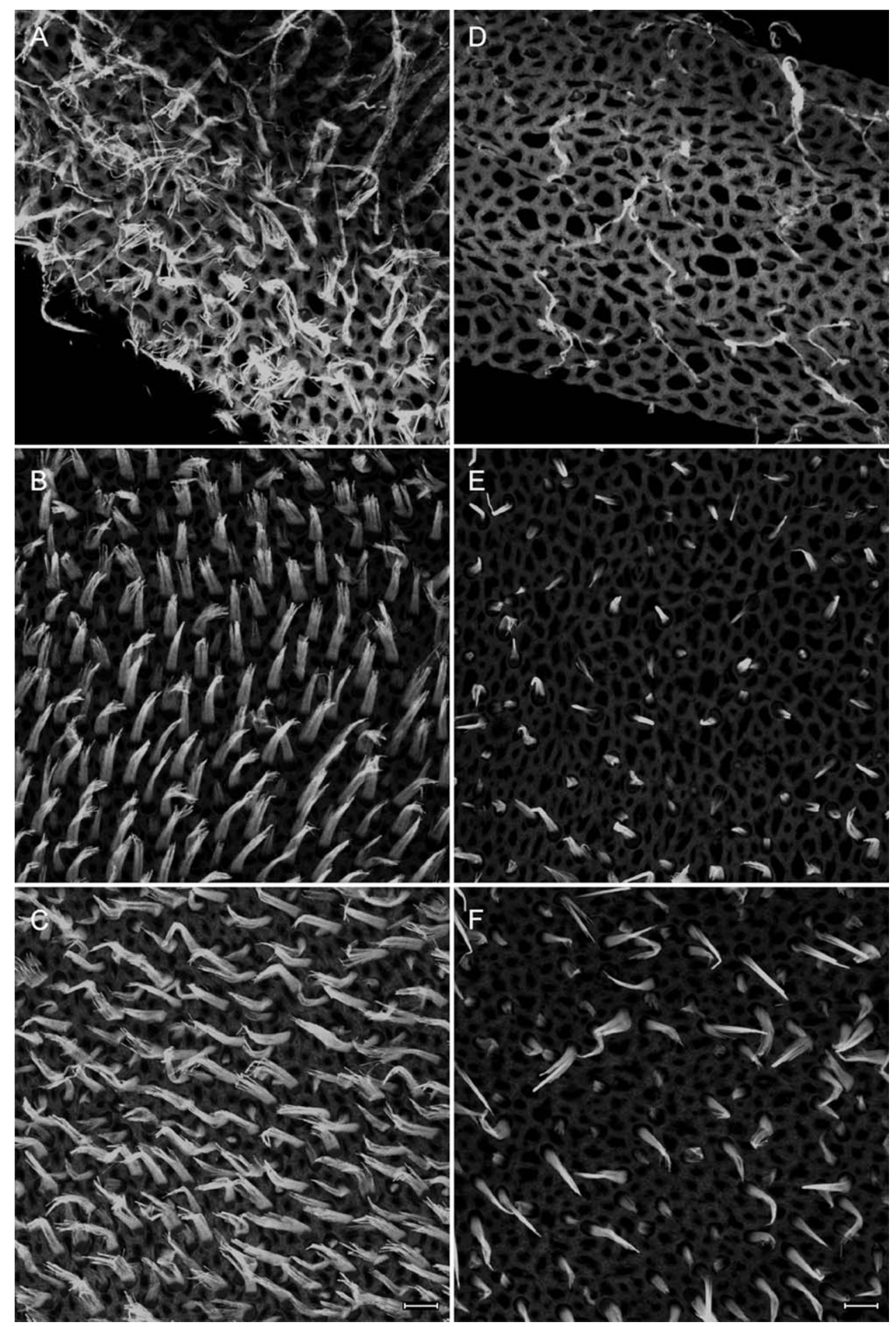

Fig. 6. Vestibular end organs harvested from guinea pigs at 2 weeks after treatment with saline $(A-C)$ and gentamicin (D-F). No observable morphological change is noted in the saline-treated ears $(A-C)$, but loss of hair cells is shown in gentamicin-treated ears (D-F). (A, D) Crista ampullaris. (B, E) Utricular maculae. (C, F) Saccular maculae. Bar $=10 \mu \mathrm{m}$
Further, the saline-treated ears revealed $100 \%$ clear oVEMPs (Fig. 4) and cVEMPs (Fig. 5). The mean nI latency, pI latency, and nI-pI amplitude of oVEMPs were $3.21 \pm 0.39 \mathrm{~ms}, 4.80 \pm 0.29 \mathrm{~ms}$, and $67.3 \pm 47.8 \mu \mathrm{V}$, respectively. The mean positive peak I latency, negative peak II latency, and amplitude I-II of cVEMPs were 6.41 $\pm 0.78 \mathrm{~ms}, 7.42 \pm 0.52 \mathrm{~ms}$, and $5.75 \pm 1.95 \mu \mathrm{V}$, respectively (Table I). In contrast, none of the gentamicintreated ears showed clear oVEMP and cVEMP (Fig. 4 and Fig. 5), exhibiting significant difference when compared with saline-treated ears $(P<.01$, Mann-Whitney $U$ test) (Table I).

Morphologically, the vestibular explants taken from guinea pigs treated with saline demonstrated normal morphology in the crista ampullaris (Fig. 6A), utricle (Fig. 6B), and saccule (Fig. 6C). However, substantial loss of hair cells was noted in the vestibular labyrinth of the gentamicin-treated ears (Fig. 6D-6F). 


\section{DISCUSSION}

In this study, gentamicin was applied locally instead of systemically in guinea pigs to generate ototoxicity without failure. On the other hand, a local inner ear drug-delivery method has become a consistent and effective way to treat inner ear disorders. Many agents are applied intratympanically in humans or animals. The categories of these agents are diverse, including for example gentamicin, steroids, antioxidants, neurotransmitters, growth factors. ${ }^{12-14}$ In addition, local viral and nonviral gene transfer for the sustained treatment of inner ear disorders also applies this method. ${ }^{15,16}$ Thus, it is essential to investigate the toxic information of each agent before it can be used clinically, and the inner ear monitoring system is therefore developed in guinea pigs to evaluate the toxic effects of any agent on the inner ear.

The ABR, caloric, oVEMP, and cVEMP tests were adopted as an inner ear monitoring system for assessing the functions of cochlea, semicircular canals, utricle, and saccule, respectively. To evaluate the efficacy of this monitoring system, guinea pigs were treated with gentamicin and saline locally in each ear, respectively. Present but elevated ABR thresholds in gentamicintreated ears associated with absent caloric, oVEMP, and cVEMP responses further support the selective vestibulotoxic effect of gentamicin. ${ }^{2}$

Via stimulation by air-conduced sound or bone-conducted vibration, VEMP can be recorded from tonically contracted cervical muscles (cVEMP) and extraocular muscles (oVEMP). ${ }^{17,18}$ The cVEMP test assesses the descending vestibular pathway as an ipsilateral sacculocollic reflex, ${ }^{19}$ whereas the oVEMP test evaluates the ascending vestibular pathway as a crossed vestibuloocular reflex. ${ }^{20}$ That is, the cVEMP evoked via air-conducted sound stimulation primarily evaluates the saccular function, ${ }^{21}$ whereas the oVEMP elicited by bone-conducted vibration predominantly originates from the utricle. $^{7}$ Therefore, $100 \%$ clear oVEMPs (Fig. 4) and cVEMPs (Fig. 5) shown in all saline-treated ears, and absent oVEMPs and cVEMPs in all gentamicin-treated ears, indicate the ablation of the otolithic receptors, which further confirms the availability of this inner ear monitoring system.

Additionally, in our recent report, ${ }^{22}$ gentamicintreated animals have demonstrated considerable damage in the saccular macula and their afferents, as well as downregulation of sodium channel Nav1.8 expression in the vestibular ganglion neurons, indicating that the toxic effect of gentamicin on the inner ear system is via damaging the inner ear receptors and afferents.

Morphologically, the cochlear and vestibular explants harvested from guinea pigs treated with gentamicin demonstrated substantial loss of hair cells in the cochlea, crista ampullaris, utricular, and saccular macula (Fig. 2 and Fig. 6), which correlate with the functional results obtained via the inner ear monitoring system. Therefore, this inner ear monitoring system can provide thorough toxicity information on the inner ear end organs and assist in the assessment of intoxication of various kinds of eardrops or agents clinically.

\section{Study Limitation}

There are some limitations in this study that need to be addressed. Because single dosage $(2.0 \mathrm{mg})$ of gentamicin eardrops in guinea pigs is enough to damage the vestibular end organs with elevated ABR thresholds, further study should focus on the optimal dose of gentamicin for deteriorating the vestibular function but preserving the cochlear function. Clinically, this unequal toxicity of gentamicin on the cochlear and vestibular parts has been used to treat intractable vertigo in Meniere's patients. With the aid of the inner ear monitoring system, one may determine the optimal dosage for intratympanic gentamicin therapy in clinical patients.

\section{CONCLUSION}

The inner ear monitoring system including $\mathrm{ABR}$, caloric, oVEMP, and cVEMP tests may help to evaluate toxicity information of the topical eardrops or agents on the inner ear end organs including cochlea, semicircular canals, utricle, and saccule.

\section{BIBLIOGRAPHY}

1. Halsey K, Skjonsberg A, Ulfendahl M, Dolan DF. Efferentmediated adaptation of the DPOAE as a predictor of aminoglycoside toxicity. Hear Res 2005;201:99-108.

2. Halmagyi GM, Fattore CM, Curthoys IS, Wade S. Gentamicin vestibulotoxicity. Otolaryngol Head Neck Surg 1994; 111:571-574.

3. Minor LB. Intratympanic gentamicin for control of vertigo in Meniere's disease: vestibular signs that specify completion of therapy. Am J Otol 1999;20:209-219.

4. Aran JM. Current perspectives on inner ear toxicity. Otolaryngol Head Neck Surg 1995;112:133-144.

5. Imamura SI, Adams JC. Changes in cytochemistry of sensory and nonsensory cells in gentamicin-treated cochleas. $J$ Assoc Res Otolaryngol 2003;4:196-218.

6. Dobie RA, Black FO, Pezsnecker SC, Stallings VL. Hearing loss in patients with vestibulotoxic reactions to gentamicin therapy. Arch Otolaryngol Head Neck Surg 2006;132: $253-257$.

7. Curthoys IS. A critical review of the neurophysiological evidence underlying clinical vestibular testing using sound, vibration and galvanic stimuli. Clin Neurophysiol 2010; 121:132-144.

8. Day AS, Lue JH, Yang TH, Young YH. Effect of intratympanic application of aminoglycosides on click-evoked myogenic potentials in guinea pigs. Ear Hear 2007;28:18-25.

9. Lue JH, Day AS, Cheng PW, Young YH. Vestibular evoked myogenic potentials are heavily dependent on type I hair cell activity of the saccular macula in guinea pigs. Audiol Neurotol 2009;14:59-66.

10. Young YH, Nomura Y, Okuno T, Hara M. Clip electrode method for recording eye movements in experimental animals. Eur Arch Otorhinolaryngol 1991;248:331-334.

11. Yang TH, Young YH. Click-evoked myogenic potentials recorded on alert guinea pigs. Hear Res 2005;205: $277-283$.

12. Gianoli GJ, Li JC. Transtympanic steroids for treatment of sudden hearing loss. Otolaryngol Head Neck Surg 2001; 125:142-146.

13. Korver KD, Rybak LP, Whitworth C, Campbell KM. Round window application of D-methionine provides complete cisplatin otoprotection. Otolaryngol Head Neck Surg 2002;126:683-689.

14. Keithley EM, Ma CL, Ryan AF, Louis JC, Magal E. GDNF protects the cochlea against noise damage. Neuroreport 1998;9:2183-2187. 
15. Staecker H, Gabaizadeh R, Federoff H, Van De Water TR. Brain-derived neurotrophic factor gene therapy prevents spiral ganglion degeneration after hair cell loss. Otolaryngol Head Neck Surg 1998;119:7-13.

16. Lalwani AK, Walsh BJ, Reilly PG, Muzyczka N, Mhatre AN. Development of in vivo gene therapy for hearing disorders: introduction of adeno-associated virus into the cochlea of the guinea pig. Gene Ther 1996;3:588-592.

17. Young YH. Vestibular evoked myogenic potentials: optimal stimulation and clinical application. J Biomed Sci 2006; 13:745-751.

18. Rosengren SM, Todd NP, Colebatch JG. Vestibular-evoked extraocular potentials produced by stimulation with bone-conducted sound. Clin Neurophysiol 2005;116: 1938-1948.

19. Uchino Y, Sato H, Sasaki M, et al. Sacculocollic reflex arcs in cats. J Neurophysiol 1997;77:3003-3012.

20. Iwasaki S, McGarvie LA, Halmagyi GM, et al. Head taps evoke a crossed vestibulo-ocular reflex. Neurology 2007; 68:1227-1229

21. Murofushi T, Curthoys IS, Topple AN, Colebatch JG, Halmagyi GM. Responses of guinea pig primary vestibular neurons to clicks. Exp Brain Res 1995;103:174-178.

22. Cheng PW, Lue JH, Lin CT, Day AS, Young YH. Assessment of gentamicin-induced vestibulotoxicity by click and galvanic vestibular-evoked myogenic potentials: a guinea pig investigation. Neurotoxicology 2010;31:121-125. 